\title{
Building Momentum in International Social and Epidemiological Research on Alcohol and Drugs: Continuing the Legacy of IJADR
}

\section{Editorial}

The International Journal of Alcohol and Drug Research (IJADR) is the official journal of the Kettil Bruun Society for Social and Epidemiological Research on Alcohol (KBS). In alignment with the Society's aims, the journal's objectives are to publish and promote social and epidemiological research on alcohol and foster a comparative understanding of alcohol use and alcohol problems internationally. The Journal also publishes papers focused on other drugs and addictive substances and has a history of soliciting and publishing papers on special issues that are likely to be of interest to its readership. Since its inception, IJADR has also sought to highlight culturally diverse views on alcohol and other drug problems, and provide a specific outlet for research from low and middle income countries. It seeks to support and publish qualitative and mixed methods papers, in addition to quantitative studies, and our strong senior editorial team reflects that capacity. IJADR has also been able to address the gender imbalances in addiction journals, as have been indicated in a paper by Mathilda Hellman (2020), as women are well represented on our editorial team.

During 2019 and 2020 the Board and the Senior Editorial team began searching for new leaders who were ready to address the current challenges IJADR was facing, and plan the future development of the journal. After a long search for a new Editor-inChief, we (Professor Neo Morojele from South Africa, and Dr Anne-Marie Laslett from Australia) were selected as Co-Editors-in-Chief of IJADR for the next five years. It is a pleasure and an honor to have been granted the opportunity to promote and develop international publications and collaborations. We look forward to revitalizing IJADR, working closely with our editors and the Board to build a strong inclusive journal that regularly publishes important international findings on alcohol and drug research. We intend to strengthen the links between the KBS and IJADR and expand collaborations with our colleagues in the field.
We would like to thank the previous Editors-inChief of IJADR (2015-2019), Mark Reed (USA), Samantha Wells (Canada) and Sandra Kuntsche (Switzerland and now Australia) and the entire editorial team, including our manuscript coordinators - Kayla Luttrell (USA), Tania Cleary (South Africa) and now Christine Buchanan (South Africa), our international and senior editors Kathryn Graham (Canada), Florian Labhart (Switzerland), Christina Chambers (USA), Jakob Demant (Denmark), Robert Mann (Canada), Kathleen Anne Parks (USA), Monica Swahn (USA) and Nazarius Tumwesigye (Nigeria), our treasurer Elin Bye (Norway), as well as our many reviewers for their dedicated and assiduous work. We also acknowledge the work of the Board of IJADR, including Jürgen Rehm (Canada), Charles Parry (South Africa), Kerstin Stenius (Finland and Sweden) and particularly Tom Babor (USA). The Board has played a key role in recent times in urging IJADR to develop a plan for the future and we look to them for ongoing advice and support.

This issue, Volume 8 Number 1 (2020) of IJADR, is the first issue to have been jointly managed by us. Its content reflects both the Journal's international character - this issue includes studies/authors from four different continents - and the methodological diversity of present-day alcohol and drug research, including quantitative original studies, systematic reviews, meta-analysis and efficacy evaluation studies.

The paper by Garretsen, van de Goor, Roeg and van de Mheen (2020) from the Netherlands summarizes the research of our own Kettil Bruun Society for Social and Epidemiological Research on Alcohol, analyzing the themes of research presented at annual symposia held between 1983 and 2017. Garretsen and colleagues demonstrate growth in KBS symposium participant numbers, continuing reliance on traditional survey methods and increasing numbers of papers with a focus on policy and prevention. 
Callinan's (2020) Australia-based paper addresses a critical international methodological concern at the core of alcohol research: the question about whether and where to set a cap on the number of drinks when you ask someone about their alcohol consumption. Callinan found that capping high levels of consumption asked about and recorded in surveys potentially significantly decreases the mean level of consumption ascertained. She recommends that the feasibility of responses should be checked in pilot studies and post-hoc by analyzing associations between consumption and related variables.

The Zhao, Li, Stockwell and Ma (2020) paper is a comprehensive and important meta-analysis of the relationship between drinking and prostate cancer in Chinese populations across the world. They found "a significantly higher risk of prostate cancer incidence among Chinese drinkers than nondrinkers, with some evidence of a dose-response relationship".

Hernandez, Cancilliere, Graves and Spirito (2020) report on a pilot study that compares the efficacy of a computer-delivered and therapist-delivered motivational interviewing intervention for reducing alcohol and other drug use among court-assigned adolescents in the United States. This is one of the first studies of its kind to be conducted among adolescents, the results of which point to the feasibility and acceptability of computer-assisted motivational interviewing interventions for adolescents and serve as an important study upon which future large scale trials may be built.

In a study using data from a large sample of adults from India, Patel and her colleagues (2020) examined the association between alcohol consumption and chronic diseases. One interesting finding was the observation of somewhat different patterns of association between alcohol consumption and self-reported versus objectively measured chronic disease. For example, selfreported depression was associated with consumption of three or more drinks per occasion, whereas both self-reported and objectively measured hypertension were associated with moderate drinking. The authors point to the need to strengthen alcohol control policies in India.

We hope you find these papers inspiring and look forward to receiving more research articles, reviews, commentaries, ideas for special issues, and other papers on social and epidemiological research concerning any of the full range of addictive substances from across the globe. With IJADR we strive to improve the relatively limited geographical and gender representation of the field of alcohol and other drug research and hope you will join us in this important mission.

\section{References}

Callinan, S. (2020). Setting a cap on the maximum average number of drinks per day in Australian survey research. The International Journal of Alcohol and Drug Research, 8(1), 7-11. https://doi.org/10.7895/ijadr.257

Garretsen, H., van de Goor, I., Roeg, D., \& van de Mheen, D. (2020). Social and epidemiological research on alcohol: Research presented at meetings of the Kettil Bruun Society between 1983 and 2017. The International Journal of Alcohol and Drug Research, 8(1), 3-6. https://doi.org/10.7895/ijadr.265

Hellman, M., Kauppila, E., Katainen, A., Kettunen, T. A., Saitz, R., \& Calver, K. (2020). Diversity in addiction publishing. International Journal of Drug Policy, 82, 102788. https://doi.org/10.1016/j.drugpo.2020.102788

Hernandez, L., Cancilliere, M. K., Graves, H., \& Spirito, A. (2020). A randomized pilot study comparing the efficacy of a therapist-delivered motivational interview to a brief computerdelivered intervention. The International Journal of Alcohol and Drug Research, 8(1), 2936. https://doi.org/10.7895/ijadr.256

Patel, S., Ram, F., Parry, C., \& Kumar Patel, S. (2020). Associations of alcohol consumption with chronic diseases, lifestyle behaviors and socioeconomic-demographic characteristics in India. The International Journal of Alcohol and Drug Research, 8(1), 38-49. https://doi.org/10.7895/ijadr.259

Zhao, J., Gao, D., Li, Y., Stockwell, T., \& Ma, J. (2020). Alcohol consumption and incidence of prostate cancer among Chinese people: A systematic review and meta-analysis. The International Journal of Alcohol and Drug Research, $\quad 8(1), \quad 12-28$. https://doi.org/10.7895/ijadr.263

Anne-Marie Laslett, PhD, MPH, MDSc, BDSc Co-Editor-in-Chief

Senior Research Fellow, Centre for Alcohol Policy Research, La Trobe University,

Australia (Australian Research Council

DE190100329)

Adjunct Senior Research Fellow, National Drug Research Institute, Curtin University, Australia President, Kettil Bruun Society for Social and Epidemiological Research on Alcohol

Neo K. Morojele, PhD

Co-Editor-in-Chief

Professor, Department of Psychology, University of Johannesburg, South Africa

Consultant, South African Medical Research Council

Honorary Professor, School of Public Health, University of the Witwatersrand, South Africa Honorary Professor, School of Public Health and Family Medicine, University of Cape Town, South Africa. 